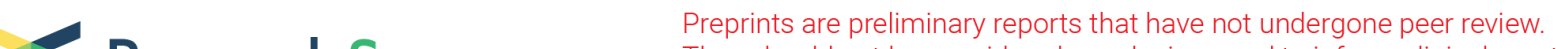

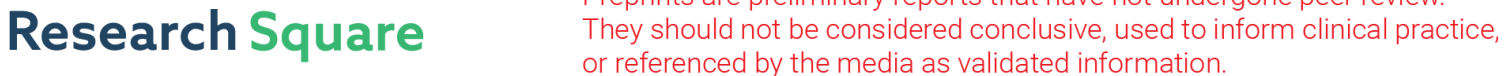

\section{Nationwide study of mortality and survival in pregnancy-related streptococcal toxic shock syndrome}

\section{Eijiro Hayata}

Toho University Omori Medical Center https://orcid.org/0000-0001-8555-3007

Masahiko Nakata ( Masahiko.nakata@med.toho-u.ac.jp)

Toho University School of Medicine https://orcid.org/0000-0002-3621-1251

Junichi Hasegawa

Sei Marianna Ika Daigaku

Hiroaki Tanaka

Mie Daigaku

Takeshi Murakoshi

Seirei Hamamatsu Byoin

Nobuaki Mitsuda

Osaka Boshi Iryo Center

\section{Akihiko Sekizawa}

Showa Daigaku

Tomoaki lkeda

Mie Daigaku

Isamu Ishiwata

Ishiwata OB and GYN Hospital

\section{Research article}

Keywords: Streptococcal toxic shock syndrome, Group A streptococci, Maternal death, Sepsis, Pregnancy

Posted Date: June 30th, 2020

DOI: https://doi.org/10.21203/rs.3.rs-39096/v1

License: (c) (i) This work is licensed under a Creative Commons Attribution 4.0 International License. Read Full License

Version of Record: A version of this preprint was published at Journal of Obstetrics and Gynaecology Research on December 21st, 2020. See the published version at https://doi.org/10.1111/jog.14619. 


\section{Abstract \\ Background}

Streptococcal toxic shock syndrome is associated with the highest rates of infection-related maternal mortality. We conducted a comparative analysis of background factors and treatment course between patients who survived and those who did not to improve our understanding of the optimal initial treatment approach for this fulminant disease.

\section{Methods:}

A retrospective observational study was conducted based on clinical data collected from two national organizations. Clinical data of patients who died and of those who survived, including background information, clinical course, and treatment administered, were collated.

\section{Results:}

No statistical differences were found between groups for age, parity, season, gestational age, or the patient's location at the onset of symptoms. After the onset of initial symptoms, survivors were administered antibiotics systematically during their first visit to a clinic $(p=0.006)$. More survivors had received treatment within 1 hour of onset of fulminant disease $(p=0.069)$. The number of fetal deaths was significantly higher in the mortality group $(p=0.003)$, while that of fetal survival was higher in the group of maternal survivors $(p=0.055)$. Maternal survivors with non-specific initial symptoms received early intervention if there was a family history of group A streptococcal infection or a positive rapid antigen test result.

\section{Conclusions}

Intensive care, including systemic administration of antibiotics, may contribute to maternal survival when administered immediately (within 1 hour) after the onset of fulminant streptococcal toxic shock syndrome. Eliciting a family history of streptococcal infection and conducting a rapid antigen test can identify patients needing early intervention.

\section{Background}

Streptococcal toxic shock syndrome (STSS) is a severe complication of invasive group A streptococcal (GAS) infection that can rapidly progress to shock and multi-organ failure (MOF) and is associated with high mortality $[1,2]$. The clinical course of STSS is particularly aggressive if it occurs during pregnancy and the puerperium. Its early symptoms (e.g. fever and upper respiratory manifestations), mimic those of a common cold, making early diagnosis difficult. Therefore, affected patients can worsen suddenly and 
develop systemic shock within days of onset of initial symptoms [3]. According to a Japanese study that analyzed all maternal deaths that occurred during pregnancy and within $\leq 42$ days after childbirth, 13 $(4.1 \%)$ of the $317(4.3 / 100,000)$ cases of STSS recorded from 2010-2017 were caused by GAS. This causative organism is responsible for the highest maternal mortality rate due to severe infection, as reported by our earlier study of the backgrounds and characteristics of maternal deaths caused by GAS $[3,4]$.

A comparative analysis of characteristics and course of treatments between patients who died and of those who survived after developing pregnancy-related STSS can reveal information that may be useful for both early detection and management of this condition. However, pregnancy-related STSS is a rare disease, making it difficult to find enough cases to conduct an epidemiological analysis. Thus, nationwide case-control analyses of the condition are lacking, although a few case series and systematic reviews on the topic are available [5-8].

The purpose of this study was to conduct a nationwide analysis of all patients diagnosed with pregnancy-related STSS caused by GAS, irrespective of the eventual outcome. We aimed to conduct a comparative analysis of background factors and treatment course between patients who survived and those who did not in order to formulate an initial approach for this fulminant disease.

\section{Materials And Methods}

\section{Study design and population}

We conducted a retrospective observational study and sourced clinical data of pregnant women diagnosed with STSS from two national organizations.

a. Data of patients who died due to STSS

The Japan Association of Obstetricians and Gynecologists (JAOG) is responsible for registering all maternal deaths and holds detailed reports on almost all maternal deaths that have occurred in Japan since 2010. In this study, we included data from all maternal deaths caused by STSS as determined by the Japan Maternal Death Exploratory Committee (JMDEC) (Chairman: Ikeda, T.) based on JAOG data from 2010-2017. JMDEC consists of doctors from several fields, including 23 obstetricians, 6 anesthesiologists, 3 pathologists, 2 forensic doctors, 2 psychiatrists, 1 emergency physician, 1 cardiologist, and 1 neurosurgeon. The JMDEC routinely analyzes causes of all maternal deaths registered with the JAOG and based on their findings, provides recommendations for decreasing maternal mortality. In Japan, maternal death is defined as that which occurs during pregnancy and within $\leq 42$ days of childbirth due to any reason that is related to pregnancy or its management, regardless of the duration and the site of gestation [9].

b. Data of patients who survived STSS 
We collated clinical data of pregnant women diagnosed with STSS who were treated from 2015 to 2017 in institutions registered with the Perinatal Research Network in Japan (PRNJ) and survived until discharge. PRNJ is an organization that includes obstetricians working at both general and local perinatal medical centers and was established to improve the overall quality of perinatal medical care. As of April 2018, 192 institutions are registered with the PRNJ, which accounts for $99 \%$ (107/108) and 29\% $(85 / 298)$ of general and local perinatal medical centers in Japan, respectively. We first conducted a primary survey of these institutions to identify eligible (survivors of STSS) patients in their records and requested their cooperation for collaborative research. If they consented to participate and shared that they had records of patients with relevant symptoms, we then sent a detailed questionnaire to collect all relevant clinical information.

\section{Case definitions of STSS}

We defined STSS cases, as specified by the Japanese Ministry of Health, Labour and Welfare (MHLW), as those that satisfied the following conditions simultaneously: 1) the patient had evidence of systemic shock with organ dysfunction (e.g., acute kidney failure, acute respiratory distress syndrome, necrotizing fasciitis); and 2) GAS was isolated and identified from otherwise sterile sites (e.g., blood, ascitic fluid, and necrotizing soft tissues) [10]. These criteria are similar to those used for defining STSS in the UK [11] and the US [12].

\section{Statistical analysis}

The Statistical Package for Social Science (SPSS) software program (Windows version 20.0J; Chicago, IL, USA) was used for data analysis.

\section{Ethical considerations}

This study was approved by the ethics committee of the Toho University Omori Medical Center before the commencement of the study (Approval No: M18055). The requirement for written informed consent was waived by the committee due to the retrospective nature of the study.

\section{Results}

One hundred and twenty-six institutions registered with the PRNJ consented to participate in this study and provided data of STSS survivors. Study patients were divided into two groups of STSS-related deaths and survivors for the comparative analysis, and the characteristics of the two study groups are presented in Table 1. We found no statistical differences between groups related to age, parity, and season, gestational age or patient location (home/hospital) at the time of symptom onset. In both groups, multiparas were more susceptible (deaths: $76.9 \%$; survivors: $86.7 \%$ ), and the disease occurred more frequently in winter and spring (deaths: $61.5 \%$; survivors: $66.7 \%$ ). The majority of patients experienced an onset of symptoms outside medical facilities (deaths: $69.2 \%$; survivors: $66.7 \%$ ). 
Table 1

Characteristics of study patients

\begin{tabular}{|c|c|c|c|}
\hline Baseline characteristics & $\begin{array}{l}\text { Dead } \\
n=13)\end{array}$ & $\begin{array}{l}\text { Survived } \\
(n=15)\end{array}$ & p-value \\
\hline \multicolumn{4}{|l|}{ Age } \\
\hline$<24$ & 0 & 2 & \multirow{4}{*}{$0.20^{*}$} \\
\hline $25-34$ & 5 & 7 & \\
\hline $35-39$ & 6 & 5 & \\
\hline $40<$ & 2 & 1 & \\
\hline \multicolumn{4}{|l|}{ Parity } \\
\hline Primipara & 3 & 2 & \multirow{2}{*}{$0.43^{* \star}$} \\
\hline Multipara & 10 & 13 & \\
\hline \multicolumn{4}{|l|}{ Onset season } \\
\hline Spring (March - May) & 3 & 4 & \multirow[t]{4}{*}{$0.99 *^{* \star}$} \\
\hline Summer (June - August) & 3 & 3 & \\
\hline Autumn (September - November) & 2 & 2 & \\
\hline Winter (December - February) & 5 & 6 & \\
\hline \multicolumn{4}{|l|}{ Gestational age at onset } \\
\hline 1st trimester & 1 & 1 & \multirow[t]{4}{*}{$0.24^{*}$} \\
\hline 2nd trimester & 4 & 2 & \\
\hline 3rd trimester & 5 & 7 & \\
\hline Postpartum & 3 & 5 & \\
\hline \multicolumn{4}{|c|}{ Patient's location at initial symptom(s) } \\
\hline At home & 9 & 10 & \multirow[t]{3}{*}{$0.57^{\star \star *}$} \\
\hline Clinic & 3 & 2 & \\
\hline Hospital & 1 & 3 & \\
\hline \multicolumn{4}{|l|}{ *Mann-Whitney's U test, } \\
\hline \multicolumn{4}{|l|}{${ }^{* *}$ Fisher's exact probability test, } \\
\hline${ }^{\star \star \star}$ Chi-square for independence tes & & & \\
\hline
\end{tabular}


Table 2 summarizes the clinical course of STSS. Patients from both groups initially experienced symptoms characteristic of the common cold, with fever being the most common (no significant intergroup difference). Among survivors, antibiotics were often administered systematically during the first visit to a medical center, after the initial onset of symptoms $(p=0.006)$. While no significant difference was observed in the time interval from the initial onset of symptoms to the development of STSS between groups, most patients in both groups reached the fulminant stage within 48 hours (deaths: 76.6\%; survivals: $80.0 \%$ ). Further, while more patients who survived had received treatment within 1 hour of onset of the fulminant stage of STSS, compared to those in the mortality group $(p=0.069)$, no statistically significant difference was observed in the time interval from onset of fulminant disease to the initiation of intensive care between both groups. The number of fetal deaths was significantly higher in the mortality group $(p=0.003)$. While fetal survival rate was not significantly different between both groups, fetal survival was observed to be higher in the group of maternal STSS survivors $(p=0.055)$. 
Table 2

Clinical course of streptococcal toxic shock syndrome in both patient groups.

\section{$\operatorname{Dead}(n=13) \quad$ Survived $(n=15) \quad p$-value}

\section{Initial symptom(s)}

Fever

9

14

$0.26^{* \star *}$

Upper respiratory tract symptoms

5

2

Upper abdominal pain

3

3

Vaginal bleeding

0

3

Lower abdominal pain

2

4

Wound infection

0

2

Initial treatment at the first visit

Observation

2

0

$0.006^{\star \star \star}$

NSAIDs

9

3

Antibiotics (oral medication)

0

1

Antibiotics (systemic administration)

2

11

Interval between initial symptom(s) and fulmination

\begin{tabular}{|c|c|c|c|}
\hline same time & 1 & 2 & $0.77 *$ \\
\hline$<24$ hours & 8 & 6 & \\
\hline $24-48$ hours & 1 & 4 & \\
\hline$>48$ hours & 3 & 3 & \\
\hline \multicolumn{4}{|c|}{ Interval between fulmination and intensive care } \\
\hline$<1$ hour & 5 & 11 & \multirow[t]{2}{*}{$0.069 * *$} \\
\hline$>1$ hour & 8 & 4 & \\
\hline
\end{tabular}

Fetal status during onset of fulminant infection

Alive

3

12

$0.003^{* * *}$

Dead

10

3

Fetal outcome

Intact survival

3

9

$0.055^{\star \star}$

Survival with disability

0

3 


\begin{tabular}{|c|c|c|c|}
\hline & $\operatorname{Dead}(n=13)$ & Survived(n = 15) & p-value \\
\hline Dead & 10 & 3 & \\
\hline \multicolumn{4}{|c|}{ *Mann-Whitney's U test; ${ }^{\star \star}$ Fisher's exact probability test; ${ }^{* \star \star}$ Chi-square for independence test } \\
\hline
\end{tabular}

Table 3 summarizes factors that prompted early intervention in the survivor group and includes factors such as characteristic symptoms, test results, and relevant medical history. Patients who developed STSS in the puerperal period were treated earlier as disease onset occurred during hospitalization. Of those patients who developed STSS in the antenatal period, 6 received aggressive therapeutic interventions (systemic administration of antibiotics) before being definitively diagnosed, because their clinical presentation had indicated the possibility of severe infection. However, patients who experienced initial, non-specific symptoms of upper abdominal pain, fever, and genital bleeding had received relevant treatment only if they had tested positive on a rapid diagnostic test for GAS or had reported a family history of GAS infection. 
Table 3

Factors that triggered therapeutic intervention in survivors of streptococcal toxic shock syndrome.

$\begin{array}{lll}\text { Gestational } & \begin{array}{l}\text { Initial } \\ \text { sympat onset }\end{array} & \begin{array}{l}\text { Time-interval } \\ \text { between onset } \\ \text { and fulminant } \\ \text { STSS }\end{array}\end{array}$

13 weeks

Fever, upper 9 hours abdominal

pain

22 weeks

Fever, upper 3 days abdominal

pain,

diarrhea
Determinants of early treatment intervention
Time-interval between

fulminant disease and intensive care

2 hours

Family history of GAS infection

3 hours

Positive of rapid diagnostic test for GAS

\begin{tabular}{|c|c|c|c|c|}
\hline 26 weeks & $\begin{array}{l}\text { Fever, } \\
\text { fatigues }\end{array}$ & 2 days & Within 1 hour & $\begin{array}{l}\text { Suspected from clinical } \\
\text { symptoms at initial visit } \\
\text { before diagnosis } \\
\text { confirmed }\end{array}$ \\
\hline 29 weeks & $\begin{array}{l}\text { Fever, limb } \\
\text { joint pain }\end{array}$ & 12 hours & Within 1 hour & $\begin{array}{l}\text { Suspected from clinical } \\
\text { symptoms at initial visit } \\
\text { before diagnosis } \\
\text { confirmed }\end{array}$ \\
\hline 32 weeks & $\begin{array}{l}\text { Fever, } \\
\text { vaginal } \\
\text { bleeding }\end{array}$ & 30 hours & Within 1 hour & $\begin{array}{l}\text { Positive of rapid } \\
\text { diagnostic test for GAS }\end{array}$ \\
\hline 33 weeks & $\begin{array}{l}\text { Fever, upper } \\
\text { abdominal } \\
\text { pain }\end{array}$ & 6 hours & Within 1 hour & $\begin{array}{l}\text { Family history of GAS } \\
\text { infection }\end{array}$ \\
\hline 34 weeks & $\begin{array}{l}\text { Fever, lower } \\
\text { abdominal } \\
\text { pain }\end{array}$ & 45 hours & 5 hours & $\begin{array}{l}\text { Suspected from clinical } \\
\text { symptoms at initial visit } \\
\text { before diagnosis } \\
\text { confirmed }\end{array}$ \\
\hline 34 weeks & $\begin{array}{l}\text { Fever, lower } \\
\text { abdominal } \\
\text { pain }\end{array}$ & 16 hours & Within 1 hour & $\begin{array}{l}\text { Suspected from clinical } \\
\text { symptoms at initial visit } \\
\text { before diagnosis } \\
\text { confirmed }\end{array}$ \\
\hline 36 weeks & $\begin{array}{l}\text { Fever, upper } \\
\text { respiratory } \\
\text { tract } \\
\text { symptoms }\end{array}$ & 59 hours & Within 1 hour & $\begin{array}{l}\text { Suspected from clinical } \\
\text { symptoms at initial visit } \\
\text { before diagnosis } \\
\text { confirmed }\end{array}$ \\
\hline 39 weeks & $\begin{array}{l}\text { Upper } \\
\text { respiratory } \\
\text { tract } \\
\text { symptoms }\end{array}$ & 21 hours & Within 1 hour & $\begin{array}{l}\text { Suspected from clinical } \\
\text { symptoms at initial visit } \\
\text { before diagnosis } \\
\text { confirmed }\end{array}$ \\
\hline $\begin{array}{l}\text { Postpartum } \\
\text { day } 1\end{array}$ & $\begin{array}{l}\text { Fever, } \\
\text { wound } \\
\text { infection }\end{array}$ & Same time & Same time & $\begin{array}{l}\text { Onset in medical } \\
\text { institutions }\end{array}$ \\
\hline
\end{tabular}




\begin{tabular}{|lllll|}
\hline $\begin{array}{l}\text { Gestational } \\
\text { ageat onset }\end{array}$ & $\begin{array}{l}\text { Initial } \\
\text { symptom(s) }\end{array}$ & $\begin{array}{l}\text { Time-interval } \\
\text { between onset } \\
\text { and fulminant } \\
\text { STSS }\end{array}$ & $\begin{array}{l}\text { Time-interval between } \\
\text { development of } \\
\text { fulminant disease and } \\
\text { intensive care }\end{array}$ & $\begin{array}{l}\text { Determinants of early } \\
\text { treatment intervention }\end{array}$ \\
\hline $\begin{array}{l}\text { Postpartum } \\
\text { day 1 }\end{array}$ & $\begin{array}{l}\text { Fever, lower } \\
\text { abdominal } \\
\text { pain }\end{array}$ & 48 hours & Same time & $\begin{array}{l}\text { Onset in medical } \\
\text { institutions }\end{array}$ \\
\hline $\begin{array}{l}\text { Postpartum } \\
\text { day 1 }\end{array}$ & Fever & 16 hours & 8 hours & $\begin{array}{l}\text { Onset in medical } \\
\text { institutions }\end{array}$ \\
\hline $\begin{array}{l}\text { Postpartum } \\
\text { day 2 }\end{array}$ & Fever & Same time & Same time & $\begin{array}{l}\text { Onset in medical } \\
\text { institutions }\end{array}$ \\
\hline $\begin{array}{l}\text { Postpartum } \\
\text { day 6 }\end{array}$ & $\begin{array}{l}\text { Fever, } \\
\text { wound } \\
\text { infection }\end{array}$ & 72 hours & Same time & $\begin{array}{l}\text { Onset in medical } \\
\text { institutions }\end{array}$ \\
\hline GAS, group A streptococcal; STSS, streptococcal toxic shock syndrome & \\
\hline
\end{tabular}

\section{Discussion}

This study had three principal findings. Firstly, no background factors (i.e. age, parity, season, gestational period, initial symptoms, and location of disease onset) were found to be different between STSS patients who survived and those who died. Secondly, intensive care tended to be initiated soon after the onset of fulminant disease (within 1 hour) in the group of survivors, since these patients were given systemic antibiotics at their first visit to a clinic where they presented with initial symptoms. Further, fetal survival despite the onset of fulminant STSS tended to be higher among the group of maternal survivors, with an associated improved prognosis of the newborn following delivery. Thirdly, in patients experiencing non-specific initial symptoms of GAS infection, such as upper abdominal pain and genital bleeding, early intervention was offered based on a positive family history of GAS infection or a positive rapid antigen test for GAS.

Background characteristics were not indicative of disease prognosis. Pregnancy-related STSS occurs more commonly in parous women and is more likely to occur in winter and spring [6]. GAS infection is seasonal and usually occurs in children, and can be transmitted either via droplet infection or contact between members of a family. Our findings also reflected this tendency in both mortality and survival groups. Several studies have reported that the maternal mortality rate decreases if antibiotics are administered within 1 hour of the diagnosis of sepsis [13-15]. The Surviving Sepsis Campaign guidelines strongly recommend initiating treatment with systemic antibiotics within 1 hour of sepsis diagnosis, since every consecutive hour of delay in antibiotic administration increases mortality by $7.6 \%$ [16]. Our study findings support this recommendation. Fulminant GAS infection is likely to progress to sepsis rapidly. If fulminant infection is suspected, the patient should be urgently transferred to a specialized center where treatment with systemic high-dose, broad-spectrum antibiotics can be initiated without awaiting confirmation of the diagnosis on culture tests [17]. This is important since the rate of fetal 
survival, and the subsequent neonatal outcome, was higher in the maternal survivor group, even with the onset of fulminant disease. We hypothesized that compared to the mortality group, patients in the survivor group were likely diagnosed at a stage where STSS was still reversible and responsive to treatment. STSS causes sepsis and MOF due to systemic GAS invasion that occurs after the initial colonization of the gravid uterus and subsequent induction of severe inflammation [18]. Consequently, much stronger uterine contractions are induced during delivery, releasing large quantities of germs and toxins into the maternal systemic circulation [19]. Intrauterine fetal death is assumed to occur during this process, due to spread of inflammation to the fetus through the uterine muscular wall, associated with concomitantly low umbilical blood flow as a result of reduced systemic perfusion in the mother due to sepsis. Therefore, if the fetus is still alive in women suspected of having STSS, therapeutic interventions that can save both mother and infant are needed, and therefore patients should be urgently transferred to a specialized medical institution that can provide intensive care for both.

Patients with non-specific symptoms of STSS received early treatment only if they reported a positive family history of streptococcal infection or tested positive for GAS antigen. Since close contact with patients with streptococcal infection is associated with the transmission of STSS [17, 20,21], it is important to ask pregnant women about their medical history and to consider GAS infection as part of the differential diagnosis of women presenting with symptoms of the common cold, e.g., sore throat. If GAS infection is suspected, the need for a rapid antigen test or the administration of antibiotics can be assessed using the Centor criteria [22]. To prevent unnecessary use of antibiotics, it is recommended that treatment should be delayed until results of the GAS rapid antigen test or throat swab culture test are available, even if a patient scores 3 or 4 points according to the Centor criteria [23]. However, since early treatment of patients with GAS infection can improve prognosis, we believe that the GAS rapid antigen test and/or throat swab culture test should be performed urgently in suspected patients. Further, empirical administration of antibiotics should be considered based on the clinical picture, even if the patient scores low as per the Centor criteria.

This study collated nationwide data for the systematic study of an uncommon but serious pregnancyrelated infection. However, it has certain limitations. Firstly, since this was a retrospective observational study designed to investigate a rare disease, evaluation of rates of incidence and prevention of STSS was impossible. In developed countries, national-level surveillance is often conducted for all patients with STSS since reporting of confirmed cases is often mandatory $[7,24,25]$. Some of these countries have instituted guidelines for the prevention of pregnancy-related GAS infections [11]. Second, it is still unclear why the results differ from previous reports with regard to the timing of STSS onset. Further prospective studies are warranted, including studies investigating the association between perinatal antibiotic use and severe infections. Based on the results of this study, the JMDEC is aiming to prospectively accumulate survival data of rare diseases, including STSS, in the future. Third, since this was a retrospective study performed using questionnaires, we cannot exclude the possibility of recall bias. It is possible that treatment effects were overrated based on doctors' experience of success with the surviving patients, while the same findings could be conversely underrated in the mortality group. 


\section{Conclusions}

No background factors were found to be predictive of mortality or survival in patients with STSS. We found that intensive care, including systemic administration of antibiotics, offered immediately (within 1 hour) after the onset of fulminant disease may contribute to better survival. In addition to evaluating clinical symptoms in affected patients, it is also important to elicit whether there is a family history of GAS infection and to promptly conduct a rapid antigen test to determine whether early intervention in affected patients is required.

\section{Abbreviations}

STSS: Streptococcal toxic shock syndrome, GAS: group A streptococcus, MOF: Multi-organ failure, JAOG: The Japan Association of Obstetricians and Gynecologists, JMDEC: The Japan Maternal Death Exploratory Committee, PRNJ: the Perinatal Research Network in Japan, MHLW: The Japanese Ministry of Health, Labour and Welfare, SPSS: The Statistical Package for Social Science

\section{Declarations}

\section{Ethics approval and consent to participate}

This study was approved by the ethics committee of the Toho University Omori Medical Center before the commencement of the study (Approval No: M18055). The requirement for written informed consent was waived by the committee due to the retrospective nature of the study.

\section{Consent for publication}

Not applicable.

\section{Availability of data and materials}

All data supporting the findings in the study are contained within the manuscript.

\section{Competing interests}

The authors declare that they have no competing interests.

\section{Funding}

This study was supported in part by Health and Labor Sciences Research Grant (Grant Number H30healthcare-general-014).

\section{Authors' contributions}


Eijiro HAYATA: Writing - Original draft preparation, Formal analysis, Investigation, Data Curation, Visualization. Masahiko NAKATA: Conceptualization, Writing - Review and editing, Supervision. Junichi HASEGAWA: Methodology, Resources, Writing - Review and Editing. Hiroaki TANAKA: Writing - Review and Editing. Takeshi MURAKOSHI: Methodology, Resources. Nobuaki MITSUDA: Resources. Akihiko SEKIZAWA: Writing - Review and Editing, Tomoaki IKEDA: Conceptualization, Methodology, Project administration, Funding acquisition. Isamu ISHIWATA: Resources, Supervision. All authors read and approved the final manuscript.

\section{Acknowledgment(s):}

This study was supported in part by Health and Labor Sciences Research Grant (Grant Number H30healthcare-general-014).

We would like to thank Editage (www.editage.com) for English language editing.

\section{References}

1. Schuitemaker N, van Roosmalen J, Dekker G, van Dongen P, van Geijn H, Gravenhorst JB. Increased maternal mortality in the Netherlands from group A streptococcal infections. Eur J Obstet Gynecol Reprod Biol. 1998;76(1):61-4. [doi: 10.1016/s0301-2115(97)00155-3] [Pubmed:9481549].

2. Sugiyama T, Kobayashi T, Nagao K, Hatada T, Wada H, Sagawa N. Group A streptococcal toxic shock syndrome with extremely aggressive course in the third trimester. J Obstet Gynaecol Res. 2010;36(4):852-5 [doi. 10.1111/j.1447-0756.2010.01259.x] [Pubmed:20666956].

3. Hasegawa J, Sekizawa A, Yoshimatsu J, Murakoshi T, Osato K, Ikeda T, Ishiwata I. Cases of death due to serious group A streptococcal toxic shock syndrome in pregnant females in Japan. Arch Gynecol Obstet. 2015;291(1):5-7. [doi: 10.1007/s00404-014-3440-0] [Pubmed:25194311].

4. Tanaka H, Katsuragi S, Hasegawa J, Tanaka K, Osato K, Nakata M, et al. The most common causative bacteria in maternal sepsis-related deaths in Japan were group A Streptococcus: A nationwide survey. J Infect Chemother. 2019;25(1):41-4 [. doi:10.1016/j.jiac.2018.10.004] [Pubmed:30377069].

5. Chuang I, Van Beneden C, Beall B, Schuchat A. Population-based surveillance for postpartum invasive group a streptococcus infections, 1995-2000. Clin Infect Dis. 2002;35(6):665-70. [doi: 10.1086/342062] [Pubmed:12203162].

6. Gustafson LW, Blaakær J, Helmig RB. Group A streptococci infection. A systematic clinical review exemplified by cases from an obstetric department. Eur J Obstet Gynecol Reprod Biol. 2017;215:3340. [doi: 10.1016/j.ejogrb.2017.05.020].

7. Lamagni TL, Darenberg J, Luca-Harari B, Siljander T, Efstratiou A, Henriques-Normark B, et al.

Epidemiology of severe Streptococcus pyogenes disease in Europe. J Clin Microbiol. 2008;46(7):2359-67. [doi: 10.1128/JCM.00422-08] [Pubmed:18463210]. 
8. Leonard A, Wright A, Saavedra-Campos M, Lamagni T, Cordery R, Nicholls M, et al. Severe group A streptococcal infections in mothers and their newborns in London and the South East, 2010-2016: assessment of risk and audit of public health management. BJOG. 2019;126(1):44-53. [doi: 10.1111/1471-0528.15415] [Pubmed:30070056].

9. Ministry of Health, Labour and Welfare Vital statistics of JAPAN 2017

Accessed 1/28/2020.

Ministry of Health, Labour and Welfare; 2017 Vital statistics of JAPAN 2017. https://www.mhlw.go.jp/english/database/db-hw/dl/81-1a2en.pdf. Accessed 1/28/2020.

10. Ministry of Health. Labour and Welfare. Implementation manual for the national epidemiological surveillance of infectious diseases program. https://www.mhlw.go.jp/english/policy/healthmedical/health/dl/implementation_manual.pdf. Accessed 1/28/2020.

11. Steer JA, Lamagni T, Healy B, Morgan M, Dryden M, Rao B, et al. Guidelines for prevention and control of group A streptococcal infection in acute healthcare and maternity settings in the UK. $J$ Infect. 2012;64(1):1-18 [doi. 10.1016/j.jinf.2011.11.001] [Pubmed:22120112].

12. Centers for Disease Control and Prevention; 1995 Case Definition. Prevention. Streptococcus Disease, Invasive, Group A (GAS) (Streptococcus pyogenes).

https://wwwn.cdc.gov/nndss/conditions/streptococcus-disease-invasive-group-a/casedefinition/1995/. Accessed 1/28/2020.

13. Ferrer R, Artigas A, Suarez D, Palencia E, Levy MM, Arenzana A, et al. Effectiveness of treatments for severe sepsis: a prospective, multicenter, observational study. Am J Respir Crit Care Med. 2009;180(9):861-6. [doi: 10.1164/rccm.200812-19120C] [Pubmed:19696442].

14. Gaieski DF, Mikkelsen ME, Band RA, Pines JM, Massone R, Furia FF, et al. Impact of time to antibiotics on survival in patients with severe sepsis or septic shock in whom early goal-directed therapy was initiated in the emergency department. Crit Care Med. 2010;38(4):1045-53. [doi: 10.1097/CCM.0b013e3181cc4824] [Pubmed:20048677].

15. Ferrer R, Martin-Loeches I, Phillips G, Osborn TM, Townsend S, Dellinger RP, et al. Empiric antibiotic treatment reduces mortality in severe sepsis and septic shock from the first hour: results from a guideline-based performance improvement program. Crit Care Med. 2014;42(8):1749-55. [doi: 10.1097/CCM.0000000000000330] [Pubmed:24717459].

16. Rhodes A, Evans LE, Alhazzani W, Levy MM, Antonelli M, Ferrer R, et al. Surviving sepsis Campaign: international guidelines for management of sepsis and septic shock: 2016. Intensive Care Med. 2017;43(3):304-77. [doi: 10.1007/s00134-017-4683-6] [Pubmed:28101605].

17. Cantwell R, Clutton-Brock T, Cooper G, Dawson A, Drife J, Garrod D, et al. Saving Mothers' Lives: reviewing maternal deaths to make motherhood safer: 2006-2008. The eighth Report of the Confidential Enquiries into Maternal Deaths in the United Kingdom. BJOG. 2011;118(Suppl 1):1-203. [doi: 10.1111/j.1471-0528.2010.02847.x] [Pubmed:21356004]. 
18. Hamilton SM, Stevens DL, Bryant AE. Pregnancy-related group a streptococcal infections: temporal relationships between bacterial acquisition, infection onset, clinical findings, and outcome. Clin Infect Dis. 2013;57(6):870-6. [doi: 10.1093/cid/cit282] [Pubmed:23645851].

19. Udagawa H, Oshio Y, Shimizu Y. Serious group A streptococcal infection around delivery. Obstet Gynecol. 1999;94(1):153-7. [doi: 10.1016/s0029-7844(99)00238-0] [Pubmed:10389739].

20. Shinar S, Fouks Y, Amit S, Pauzner D, Tarabeia J, Schechner V, Many A. Clinical characteristics of and preventative strategies for Peripartum Group A streptococcal infections. Obstet Gynecol. 2016;127(2):227-32. [doi: 10.1097/AOG.0000000000001238] [Pubmed:26942347].

21. Lappin E, Ferguson AJ. Gram-positive toxic shock syndromes. Lancet Infect Dis. 2009;9(5):281-90. [doi: 10.1016/S1473-3099(09)70066-0] [Pubmed:19393958].

22. Centor RM, Witherspoon JM, Dalton HP, Brody CE, Link K. The diagnosis of strep throat in adults in the emergency room. Med Decis Mak. 1981;1(3):239-46. [doi: 10.1177/0272989X8100100304] [Pubmed:6763125].

23. Mclsaac WJ, Kellner JD, Aufricht P, Vanjaka A, Low DE. Empirical validation of guidelines for the management of pharyngitis in children and adults. JAMA. 2004;291(13):1587-95. [doi: 10.1001/jama.291.13.1587] [Pubmed:15069046].

24. Nelson GE, Pondo T, Toews KA, Farley MM, Lindegren ML, Lynfield R, et al. Epidemiology of Invasive Group A streptococcal infections in the United States, 2005-2012. Clin Infect Dis. 2016;63(4):47886. [doi: 10.1093/cid/ciw248] [Pubmed:27105747].

25. Diseases Nlol

Annual surveillance data (notifiable diseases)

Accessed 1/28/2020.

Diseases Nlol. Annual surveillance data (notifiable diseases). https://www.niid.go.jp/niid/en/survei/2085-idwr/ydata/6062-report-ea2014-30.html. Accessed $1 / 28 / 2020$. 